\title{
The postnatal development of the mucosal immune system and mucosal tolerance in domestic animals
}

\author{
Mick BAILEY*, Karin HAVERSON \\ School of Clinical Veterinary Science, University of Bristol, Langford House, \\ Langford, Bristol BS40 5DU, United Kingdom
}

(Received 5 July 2005; accepted 16 December 2005)

\begin{abstract}
The mucosal immune system is exposed to a range of antigens associated with pathogens, to which it must mount active immune responses. However, it is also exposed to a large number of harmless antigens associated with food and with commensal microbial flora, to which expression of active, inflammatory immune responses to these antigens is undesirable. The mucosal immune system must contain machinery capable of evaluating the antigens to which it is exposed and mounting appropriate effector or regulatory responses. Since the immune system is likely to have evolved initially in mucosal tissues, the requirement to prevent damaging allergic responses must be at least as old as the adaptive immune system, and studies of the mechanisms should include a range of non-mammalian species. Despite the importance for rational design of vaccines and for control of allergic reactions, the mechanisms involved are still largely unclear. It is not clear that the classical experimental protocol of "oral tolerance" is, in fact, measuring a biologically important phenomenon, nor is it clear whether tolerance is regulated in the evolutionarily recent organised lymphoid tissue (the lymph nodes) or the more ancient, diffuse architecture in the intestine. The capacity of the immune system to discriminate between "dangerous" and "harmless" antigens appears to develop with age and exposure to microbial flora. Thus, the ability of an individual or a group of animals to correctly regulate mucosal immune responses will depend on age, genetics and on their microbial environment and history. Attempts to manipulate the mucosal immune system towards active immune responses by oral vaccines, or towards oral tolerance, are likely to be confounded by environmentally-induced variability between individuals and between groups of animals.
\end{abstract}

mucosal immune system / tolerance / oral tolerance / allergic response / immune development

\section{Table of contents}

1. Introduction

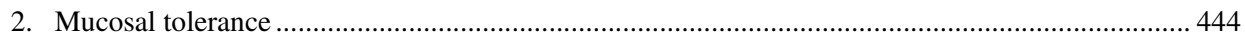

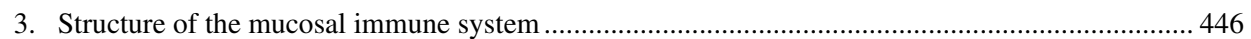

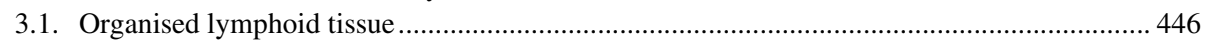

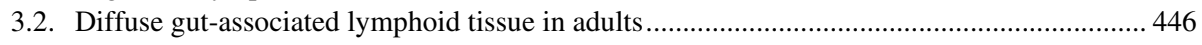

3.3. Development of the diffuse lymphoid architecture in the neonate .........................................4 447

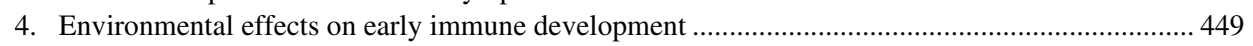

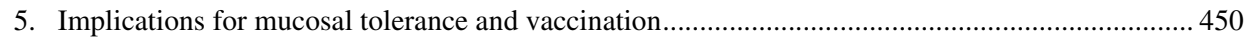

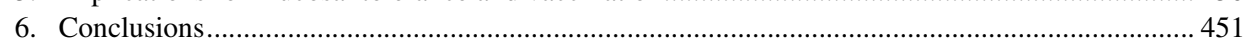

* Corresponding author: mick.bailey@ bristol.ac.uk 


\section{INTRODUCTION}

The study of the development of mucosal immune systems of our domestic species is of importance for a variety of reasons. Clearly, they are of direct economic interest as food sources or as our companions. In addition, they offer us some of the accessibility of rodents together with the advantages of longevity and size more closely approaching that of humans, when investigating more fundamental aspects of immune development in neonates. Specifically, surgical access to the foetus and to the gastrointestinal tract is possible in large domestic species. Finally, their phylogenetic diversity makes them particularly suitable to highlight evolutionary principles to complement the knowledge gained from the more traditional objects of our research: rodents and humans.

Studies over several decades have demonstrated that the mucosal immune system has properties distinct from the more thoroughly studied systemic immune system and many of these properties are reviewed elsewhere in this issue. Importantly, it has become clear that responses to antigens at mucosal surfaces must be tightly controlled in order to prevent tissue damage. That is, expression of active immune responses to harmless antigen, whether from food or from true commensal bacteria, may be undesirable in the intestine and that some form of immunological tolerance may be the normal outcome of recognition of these antigens. A number of well-characterised mucosal inflammatory diseases of humans, including inflammatory bowel disease (IBD), celiac disease and food allergy, appear to be associated with loss of tolerance to "harmless" antigens [34], and several diseases in domestic species may have a similar aetiology (IBD and food allergies in cats and dogs, postweaning diarrhoea in piglets). Although considerable progress has been made in defining the effector mechanisms by which active responses or tolerance are expressed, the mechanisms which determine which of the two outcomes actually occur after recognition of any specific anti- gen are still largely unclear. Understanding this process is the "holy grail" of mucosal immunology, since the ability to manipulate the underlying mechanisms will allow rational, rather than empirical, design of mucosal vaccines and of therapies for controlling autoimmune and allergic disease.

In this review, we will discuss models currently used for dissecting the mechanisms by which mucosal sites discriminate between dangerous and harmless antigens (the phenomena of tolerance and active, defensive responses, respectively). We will consider the possibility that the diffuse lymphoid tissue of the intestine contributes to the process of discrimination in mature animals. Since this tissue develops slowly after birth, the ability of neonates to mount appropriate immune responses may also require a considerable time period and appropriate environmental factors to develop.

\section{MUCOSAL TOLERANCE}

It has been widely accepted that immune responses to harmless antigens at mucosal surfaces must be controlled in order to prevent inflammation, loss of function and allergic disease. For the purposes of this review, we will define this absence of local inflammatory response to harmless antigen as "mucosal tolerance". To confirm mucosal tolerance, studies in mice have repeatedly demonstrated that animals given a novel protein antigen orally, either by gavage or in food or drinking water, respond poorly when the homologous antigen is injected systemically with adjuvant [15]. This model of orally-induced systemic tolerance (socalled "oral tolerance") has been extensively used to demonstrate mechanisms including regulatory T-cells and anergy or deletion of antigen-specific T-cell clones [18]. Clearly, the assumptions underlying these studies are that the mechanisms responsible for the lack of a local inflammatory response (mucosal tolerance) and for orally-induced systemic tolerance (oral tolerance) are the same. However, the classical oral tolerance protocol has a number of features which 
suggest that it may not be directly testing the presence of mucosal tolerance.

Firstly, the feeding of novel protein antigens is frequently associated with the presence of mucosal IgA responses despite the appearance of systemic oral tolerance. That is, local immune responses, albeit noninflammatory, can occur in animals which are systemically tolerant. Secondly, even in rodent studies, the extent of oral tolerance is variable. Early studies demonstrated strong genetic influences on the extent of systemic tolerance induced by feeding, some strains tolerising well, others poorly. However, the mouse strains which do not tolerise well to experimentally administered antigens do not apparently suffer from allergic reactions to the normal components of their diet. Consistent with this, several mouse models in which oral tolerance does not occur have been developed to study the mechanisms: similarly, these mice also have no apparent difficulty in controlling responses to their normal diet. Thirdly, dose of orally administered antigen appears to be important, "high" doses causing tolerance while "low" doses result in priming. This observation, which has been well documented, has been used to account for anomalous results in a number of oral tolerance experiments. Finally, the ability to develop oral tolerance is acquired with age and exposure to microbial flora in rodents. Oral administration of antigen to newborn mice has been reported to result in priming for a subsequent response to injected antigen, while germ-free mice do not develop oral tolerance to the same extent as conventional or specifically-colonised animal.

Relatively few studies of the phenomenon of oral tolerance have been carried out in domestic species, but those that do also suggest that the phenomenon is variable and age-dependent. A frequently-observed features in domestic species (and in human infants) which differs from the protocols in laboratory rodents is the appearance of systemic, IgG antibody to fed proteins after the initial feed. The problem of feeding large amounts of unprocessed soya to calves has been well documented and associated with the persistent expression of active, IgG antibody responses to soya proteins [28]. Similarly, piglets weaned onto soya- or eggbased diets developed levels of antibody comparable to those produced after primary systemic injection [7] while 7-9 month old cats fed soya or casein diets also developed serum antibody [14]. It may be important that the amount of protein antigen fed in these experiments was much higher (potentially, several grams per day) than even the "high" doses given to rodents. In chickens, a range of protein antigens administered in drinking water to adults was immunogenic, while in newly hatched chicks it was tolerogenic [35].

In target species, the level of systemic tolerance achieved is also variable. In young piglets either abruptly or gradually weaned onto soya-based diets, tolerance appeared to take some time to develop [4, 37]. In adult humans, feeding of keyhole limpet haemocyanin resulted in variable depression of T-cell responses but in priming of B-cell responses [30]. In some experiments with five week old pigs, dose of antigen was important as in rodents, low doses resulting in priming while higher doses resulted in tolerance [51]. Interestingly, the doses used in these experiments were calculated from the high and low doses given in mouse experiments, rather than from dietary experiments, suggesting that fed proteins antigens may prime at low doses, generate classical oral tolerance without an initial antibody responses at intermediate doses and, at the high doses present in single-source diets, trigger strong primary responses which are less easy to tolerise.

Thus, the ability of fed proteins to generate tolerance is dependent on age of the target animal, species and commensal microbial flora such as that present in the intestine (see below Section 4). In addition, failure to generate oral tolerance can occur in animals which, apparently, are still capable of regulating local mucosal responses to antigen 
in their normal diets. Where immune responses to diet are associated with intestinal disturbance, it is largely in young animals. For this reason, we consider that it is important to specify the age and environment of the target species in experiments on oral immunisation and tolerance and to examine local, mucosal tolerance where possible.

\section{STRUCTURE OF THE MUCOSAL IMMUNE SYSTEM}

The concept that the immune system consists of distinct subsystems, each of which is primarily responsible for a particular function, is fundamental to the study of immunology. In some situations, these subsystems are clearly structurally and functionally distinct. Thus, in mammals, there is clear distinction between primary lymphoid tissue, such as the thymus, and secondary lymphoid tissue such as the spleen and organised lymph nodes, and different rules determine the outcome of antigen-recognition. However, in contrast to the thymus and spleen, which appear to be of evolutionary old origin, similar to the age of the adaptive immune system itself, bone marrow, lymph nodes and Peyer's patches are all evolutionarily more recent, suggesting that a functional immune system must be possible without them. The earliest forms of secondary lymphoid tissue were diffuse aggregations and infiltrations in the intestinal wall [60].The implication is that many of the functions which we associate with organised lymphoid tissues in mammals (collections of B-cell follicles and associated $\mathrm{T}$-cell zones) originally took place in more diffuse aggregations of leucocytes in mucosal tissues. Consistent with this idea, immunologically-related genes appear to be expressed preferentially in the intestine in the protochordate amphioxus and in the jawless lampreys $[50,59]$. Since mucosal tissues are permanently exposed to both harmless as well as harmful antigens, mechanisms must exist which activate appropriate, but differ- ent responses to different types of antigens. However, it seems dangerous to assume that all the functions need to take place in organised lymphoid tissue unless there is clear evidence that they do not take place elsewhere. The traditional division of mucosal lymphoid tissue into organised and diffuse lymphoid tissues, with the organised lymphoid tissue receiving by far the most detailed investigation, may have led us to miss important mechanisms associated with the diffuse lymphoid sites of small and large intestine.

\subsection{Organised lymphoid tissue}

The organised lymphoid tissues associated with the intestine include the Peyer's patches and mesenteric lymph nodes. Peyer's patch like structures have also been reported from other mucosal tissues such as stomach [22] or larynx [21]. The role of the Peyer's patches $[38,57,58]$ and the mesenteric lymph nodes as inductive sites for mucosal immune responses is well established and will not be discussed much further in this review. Similarly, it is of interest that the single continuous ileal Peyer's patch differs in structure from the jejunal Peyer's patches in many domestic species such as sheep [23,41,43], cattle [57, 58], pigs [2, 3, 8], dogs [29] and buffalo [1] and may act as a primary lymphoid organ involved in the generation of a B cell repertoire, as does the chicken bursa of Fabricius $[2,42]$.

\subsection{Diffuse gut-associated lymphoid tissue in adults}

The diffuse epithelial and connective tissue of the gut contains large numbers of leucocytes in adult pigs [25], cattle [17], sheep [40], dogs [20], cats [55] and chicken [54], and it has been estimated that as many as $7 \%$ of all leucocytes are found in this site [11]. In mammals, at least three diffuse immunological compartments can be identified within the mucosa. In the epithelium of the domestic species, the predominant lymphocyte 
population express the $\mathrm{CD} 8 \alpha \beta$ co-receptor, although unconventional subsets of T-cells expressing a CD8 $\alpha \alpha$ homodimer and the TCR $\gamma \delta$ chains have been described [27]. Despite considerable work which has identified site-specific adhesion molecules and gene expression, the function of these cells is still unclear, although there is some evidence that they may play a role in the maintenance of epithelial integrity and immune regulation [27].

Similarly, the lamina propria underneath the epithelium is well supplied with leucocytes. The populations present in many species are heterogenous and apparently randomly distributed. In contrast, the immunological organisation of the lamina propria in the pig intestine shows a high level of organisation [56]. Antigen-presenting cells expressing MHC II are present in large numbers in the lamina propria of many species. In adult pigs, they have been characterised as functional, immature, dendritic cells [26], which are described in more detail in a review article in this issue by Haverson and Riffault [24]. These dendritic cells are present in large numbers within the villi and co-localise with T-cells expressing the CD4 co-receptor in the pig. In addition, the endothelium of the capillary plexus underlying the epithelial basement membrane also expresses MHC class II molecules in the pig in levels comparable with dendritic cells $[26,56]$, and clustering of T-cells, dendritic cells and MHCII+ endothelium occurs $[32,33]$. This clustering may provide a complex antigen-presenting environment in sites exposed to environmental antigens.

The third compartment, clearly distinct in the pig but not so clear in other mammalian species, is the lamina propria around the intestinal crypts. Cells staining for immunoglobulins (predominantly IgA, presumably plasma cells) occur here rather than in the villi, with few T-cells or dendritic cells, but with myeloid cells with the characteristics of macrophages and granulocytes [52].
Functionally, there is increasing evidence that the dominant role of the diffuse mucosal tissue may be immune regulation rather than active defensive responses. The dendritic cells in this site are immature, with high levels of cytoplasmic MHC II and expressing the low affinity FcyRIII. Such immature dendritic cells have been implicated in regulatory responses. However, dendritic cells are highly plastic cell types and may easily be switched from regulatory to active responses [36], providing a mechanism for appropriate immune responses to either harmless commensals or pathogens. CD4+ T-cells respond to polyclonal activation by upregulation of the IL-2R (CD25), a small transient burst of IL-2 secretion, followed by apoptosis [6]. Lamina propria cells also produce high levels of IL-4 and IL-10, although the exact cellular origin is not yet known.

Thus, the mucosal diffuse immunological compartments outside the Peyer's patches and mesenteric lymph nodes have a longer evolutionary history and can show significant organisation. The unusual cytokine milieu of mucosal T-cells and their relative inability to proliferate suggests that they may be strongly regulated, either by local cytokine environment or at the stage of antigen presentation. It is not unreasonable, therefore, to predict that this architecture may contribute significantly to the function of the mucosal immune system.

\subsection{Development of the diffuse lymphoid architecture in the neonate}

Despite the size of the immunological component of the mucosa in adults, only small numbers of leucocytes are present in this tissue at birth or hatching. In particular, newborn piglets have essentially no leucocytes, despite the more advanced development of piglets at term compared to human or rodent neonates [44, 53]. This is true for lamina propria leucocytes of any type, including antigen presenting cells, T-cells or B cells $[9,45,46]$ and unpublished 
Table I. Stages in the development of the mucosal immune system of the neonatal piglet.

\begin{tabular}{lcc}
\hline Stage 1 & The newborn pig & $\begin{array}{c}\text { Small numbers of antigen-presenting cells } \\
\text { Few T-cells }\end{array}$ \\
& & Essentially no plasma cells \\
\hline Stage 2 & 1 day to 2 weeks & $\begin{array}{c}\text { Appearance of unusual CD2+CD4-CD8- and CD2+CD4-CD8 } \alpha \alpha \text { T-cells } \\
\text { in epithelium and lamina propria }\end{array}$ \\
& & $\begin{array}{c}\text { Appearance of some activated CD4+ T-cells in lamina propria } \\
\text { Influx of MHCII+ cells in lamina propria }\end{array}$ \\
& & Mature memory CD4+ T-cells in lamina propria \\
Stage 3 & 2 weeks to 4 weeks & IgM+ B cells, predominantly in crypt areas \\
\hline Stage 4 & 4 weeks to 6 weeks & Appearance of memory CD8+ T-cells in epithelium and lamina propria \\
& & IgA+ B cells, predominantly in crypt areas \\
\hline
\end{tabular}

data $^{1,2}$. The relatively impermeable epitheliochorial placenta of the pig, which does not permit the transfer of macromolecules from sow to foetus, either antibody or exogenous antigen, makes the newborn piglet entirely immunologically naïve and may explain this profound lack of immune development of the newborn piglet. This fact has made the pig the model of choice for studies of the impact of environmental factors on immune development.

It has been shown that these leucocyte populations appear in conventional pigs in a clearly staged time course, where different phases can be distinguished (Tab. I) $[9,44$, 53]. Strongly MHC II+ cells, characterised as dendritic cells by co-expression of CD45, CD16 and other myeloid markers [26] appear relatively quickly and in large numbers in this site, within the first week of age [32]. Initially, a subset expresses CD14, but in older animals, MHC II+CD45+CD16+ cells lack CD14. This suggests that some of these dendritic cells may be derived from

\footnotetext{
${ }^{1}$ Haverson K., et al., Leucocyte migration into jejunum in response to association with selected commensal gut bacteria of germfree piglets, Proceedings IVth meeting of the European Mucosal Immunology Group (EMIG), 2004.

2 Harris C., et al., An investigation into the development of lamina propria lymphocytes in preweaning and post-weaning piglets, Proceedings IVth meeting of the European Mucosal Immunology Group, 2004.
}

blood monocytes, and may explain the fact that there appears to be some controversy about the classification of antigen-presenting cells in the gut as dendritic cells or macrophages.

In contrast, T-cells appear more slowly. The T-cell population itself can be shown to undergo a phased pattern of appearance [53]. An unusual cell type, characterised by the expression of CD2, but lacking CD4 and $\mathrm{CD} 8$, has recently been shown to co-express CD3 and can therefore be classified as CD4-CD8- T-cells. Together with a second T-cell population, characterised as $\mathrm{CD} 2+\mathrm{CD} 3+\mathrm{CD} 4-\mathrm{CD} 8 \alpha \alpha+$, they form the dominant $\mathrm{T}$-cells migrating into the jejunal tissue during the first week to ten days, and can still be found in adult animals, albeit in reduced proportions. These cells appear to have characteristics similar to the subset of thymus-derived cells with re-arranged TCR, but lacking co-receptors, which have been shown to leave the chicken thymus early and acquire $\mathrm{CD} 8 \alpha \alpha$ expression in the gut [31]. Similarly, CD4-negative CD8 $\alpha \alpha$ intraepithelial T lymphocytes have been described in rodents and have been included in the broad classification of "unconventional" or "type B" T-cells, suggested to be involved in a number of functions including immune regulation [27]. Interestingly, while conventional CD4+ and CD8 $\alpha \beta+$ T-cells in this site in adult animals express low levels of CD45RC, consistent with advanced 
memory status, a significant proportion of these unusual, $\mathrm{CD} 2+\mathrm{CD} 3+\mathrm{CD} 4-\mathrm{CD} 8 \alpha \alpha+$ T-cells express moderate to high levels of CD45RC, suggesting that they may be less antigen-experienced. High CD25 expression during the early time points, i.e. the first week to ten days of life, also suggests that they arrive with or acquire an activated status in the gut of very young animals [53].

During the second and third week of life, increasing numbers of CD4+ T-cells appear. Like the CD4-CD8 $\alpha \alpha+$ T-cells, CD4+ $\mathrm{T}$-cells appear in the very young animals with signs of recent activation: that is, expressing high levels of CD25 and also CD8 $\alpha \alpha$ (the expression of CD8 $\alpha \alpha$ on pig CD4+ cells has been described in other tissues and has been associated with memory status, [48]) and moderate levels of CD45RC, suggesting that these are cells with recent antigenic activation, in transit towards a memory status. This contrasts with the cellular characteristics of CD4+ T-cells in animals older than 12 days, which by phenotype are resting cells but of advanced memory status (lack of CD45RC, lower levels of CD8 $\alpha \alpha$ and CD25, high levels of SwC1) and respond to polyclonal activation by expression of IL-4 mRNA but not IL-2.

Finally, considerable numbers of true cytotoxic T-cells, characterised by high levels of CD8, appear. Significant numbers are only observed after the third week of life, although, again, a small proportion of such cells can be found as early as the first week. Like the other T-cells, the CD 8 hi cells arriving in the youngest pigs show signs of cellular activation and are in the early stages of a memory phenotype, whereas CD $8^{\text {hi }}$ in older animals are resting, advanced memory cells. Other late arrivals in the gut are IgA+ plasma cells, which have been reported to appear in significant numbers as late as 3-6 weeks [10].

Summarising, the final architecture characteristic of the diffuse lymphoid tissue of the gut is not achieved until the pig is approximately six weeks old, containing large numbers of dendritic cells, CD4+
T-cells of resting, advanced memory phenotype, transcribing IL-4 but unable to secrete IL-2 and responding to further activation by apoptosis. If this architecture is involved in determining the outcome of antigen recognition (active responses or tolerance), this phased development may provide an explanation of the differences in tolerance induction in adult and neonatal animals. In the next section, we will discuss the effects of environment on this development.

\section{ENVIRONMENTAL EFFECTS ON EARLY IMMUNE DEVELOPMENT}

Although the previous section has presented the development of the diffuse organisation of the intestinal mucosa almost as a predetermined "programme", there is strong evidence that its development is heavily dependent on environmental factors such as maternal colostrum and milk, diet and, in particular, the resident microflora of the gut.

Colostrum is a crucial source of passive immunity for piglets because it contains the immunoglobulin molecules IgM, IgG, IgA. In addition, it provides energy and growth factors for the developing digestive tract in the early period after birth [19, 39]. The antigen-non-specific importance of early intake of colostrum has been shown in many studies: decreased apoptosis rates and stimulated villus development in the duodenum were found at eight days after birth in calves with access to colostrum [12]. In addition to antibody, antigen can also be transferred via colostrum and milk and has been suggested to affect the subsequent immune responses of the neonate. Thus, piglets of sows fed an ovalbumin-containing diet during gestation and lactation had reduced levels of diarrhoea when weaned onto egg-containing diets and, in some cases, lower antibody response to the fed ovalbumin [49]. The transfer of antigen itself may be the causative factor: newborn piglets given soya protein by stomach tube also had a reduced 
antibody response when subsequently weaned onto soya diets [5].

Although colostrum and maternal milk have clear effects on the development of the entire animal and, as discussed on the development of oral tolerance, the dominant effect on the immune development of the mucosal immune system appears to be the presence of a commensal gut flora. This has been demonstrated by many studies in germ-free pigs, which show an almost total lack of immune development of both the organised [8] as well as the diffuse lymphoid tissue $[8,44]$. In newborn and germfree piglets, usage of variable $(\mathrm{V})$ gene segments in rearrangements of the immunoglobulin heavy chain locus is also limited. In conventional piglets or in piglets specifically colonised with flora, $\mathrm{V}$-segment usage in the intestinal mucosa expands, indicating that microbial colonisation drives expansion of repertoire, as well as compartments. Consistent with this, germ-free pigs mount poor specific systemic antibody responses [13], unless colonised with commensal flora. Even mono-association with a single commensal appears to be able to promote both a specific and a polyclonal expansion of $\operatorname{IgM}, \operatorname{IgG}$ and $\operatorname{IgA}$ secreting lymphocytes in the mesenteric lymph nodes, spleen and Peyer's patches [16].

Thus, environmental influences on development of the mucosal immune system may also contribute to differences between neonates and adults in their response to harmless antigens associated with food and commensal bacteria. Specifically, the observations provide a basis for the poor ability of germ-free animals to develop experimental oral tolerance.

\section{IMPLICATIONS FOR MUCOSAL TOLERANCE AND VACCINATION}

We have discussed the observed variation in the ability of animals to develop experimental oral tolerance, depending on species, genetics, age and environment and provided possible reasons for this variation. We have also suggested that experimental oral tolerance may not be an absolute correlate of mucosal tolerance. We shall finish by discussing the possible implications of these observations.

Firstly, it is clearly undesirable that our domestic species mount active, inflammatory responses to harmless antigens of food or commensal bacteria. Such responses are likely to be associated with loss of digestive and absorptive function and with decreased growth rates. An association of this type has been suggested between immune responses to novel diet or bacterial strains and postweaning diarrhoea in piglets. Husbandry manipulations involving changes in diet should take into account the possibility of inappropriate immune responses, particularly in neonates. Clearly, if the development of the mucosal immune system is required before young piglets can mount appropriate responses to antigen (active responses or tolerance), it will be important to delay weaning until this has occurred or to manipulate development to occur earlier. Definitively establishing the local mechanisms involved in regulating responses in the developing mucosa will be essential if this is to occur.

Secondly, we also have a need to vaccinate domestic species against pathogens, usually as young animals. In addition, mucosal vaccines are perceived as desirable in many cases, either because the specific pathogen infects across mucosal surfaces or because of the ease of delivery. However, as we have seen, induction of tolerance is variable in neonates and will depend on interactions between species, age, dose and environment. This is likely to make empirically developed vaccines unpredictable in their effects, potentially triggering variable degrees of tolerance or active responses depending on the context in which they are used. This is particularly true of novel developments such as the use of feed plants made transgenic for important pathogen 
epitopes [47]. While some of these have shown immunogenicity and even protection in some cases, their effectiveness needs to be determined across a range of conditions of age and environment of the target species before they can be assumed to be predictable. The future development of safe, reliable vaccines will depend on detailed understanding of the mechanisms involved in determining the outcome of antigen recognition in the intestine, and of the factors influencing the development of those mechanisms.

\section{CONCLUSIONS}

The immunological structure of mucosal tissue develops slowly after birth and is largely driven by environmental factors. Therefore, the ability of neonates to mount appropriate immune responses may also require a considerable time period and appropriate environmental factors to develop. We have considered the possibility that the diffuse lymphoid tissue of the intestine contributes to the process of discrimination between harmless and harmful antigens in mature animals. However, this system appears to be highly complex and is as yet incompletely understood. Empirical attempts at its manipulation are therefore unpredictable and possibly counterproductive.

\section{REFERENCES}

[1] Alboghobeish N., Nejat H.H., Intestinal Peyer's patches of buffalo, Indian J. Anim. Sci. 69 (1999) 553-555.

[2] Andersen J.K., Takamatsu H., Oura C.A.L., Brookes S.M., Pullen L., Parkhouse R.E.M., Systematic characterization of porcine ileal Peyer's patch: I. Apoptosis-sensitive immature B cells are the predominant cell type, Immunology 98 (1999) 612-621.

[3] Andersen J.K., Takamatsu H., Pullen L., Parkhouse R.M.E., Systematic characterization of porcine ileal Peyer's patch: II. A role for CD154 on T cells in the positive selection of immature porcine ileal Peyer's patch B cells, Immunology 98 (1999) 622-629.
[4] Bailey M., Miller B.G., Telemo E., Stokes C.R., Bourne F.J., Specific immunologicalunresponsiveness following active primary responses to proteins in the weaning diet of piglets, Int. Arch. Allergy Immunol. 101 (1993) 266-271.

[5] Bailey M., Miller B.G., Telemo E., Stokes C.R., Bourne F.J., Altered immune-response to proteins fed after neonatal exposure of piglets to the antigen, Int. Arch. Allergy Immunol. 103 (1994) 183-187.

[6] Bailey M., Plunkett F., Clarke A., Sturgess D., Haverson K., Stokes C., Activation of T cells from the intestinal lamina propria of the pig, Scand. J. Immunol. 48 (1998) 177-182.

[7] Bailey M., Haverson K., Miller B., Jones P., Sola I., Enjuanes L., Stokes C.R., Effects of infection with transmissible gastroenteritis virus on concomitant immune responses to dietary and injected antigens, Clin. Diagn. Lab. Immunol. 11 (2004) 337-343.

[8] Barman N.N., Bianchi A.T.J., Zwart R.J., Pabst R., Rothkotter H.J., Jejunal and ileal Peyer's patches in pigs differ in their postnatal development, Anat. Embryol. 195 (1997) 41-50.

[9] Bianchi A.T., Zwart R.J., Jeurissen S.H., Moonen-Leusen H.W., Development of the B- and T-cell compartments in porcine lymphoid organs from birth to adult life: an immunohistological approach, Vet. Immunol. Immunopathol. 33 (1992) 201-221.

[10] Bianchi A.T.J., Scholten J.W., Leusen B.H.W.M., Boersma W.J.A., Development of the natural response of immunoglobulin secreting cells in the pig as a function of organ, age and housing, Dev. Comp. Immunol. 23 (1999) 511-520.

[11] Binns R.M., Organization of the lymphoreticular-system and lymphocyte markers in the pig, Vet. Immunol. Immunopathol. 3 (1982) 95-146.

[12] Blattler U., Hammon H.M., Morel C., Philipona C., Rauprich A., Rome V., HuerouLuron I., Guilloteau P., Blum J.W., Feeding colostrum, its composition and feeding duration variably modify proliferation and morphology of the intestine and digestive enzyme activities of neonatal calves, J. Nutr. 131 (2001) 1256-1263.

[13] Butler J.E., Weber P., Sinkora M., Baker D., Schoenherr A., Mayer B., Francis D., Antibody repertoire development in fetal and neonatal piglets. VIII. Colonization is required for newborn piglets to make serum antibodies to T-dependent and Type 2 T-independent antigens, J. Immunol. 169 (2002) 6822-6830. 
[14] Cave N.J., Marks S.L., Evaluation of the immunogenicity of dietary proteins in cats and the influence of the canning process, Am. J. Vet. Res. 65 (2004) 1427-1433.

[15] Challacombe S.J., Tomasi T.B., Systemic tolerance and secretory immunity after oral immunization, J. Exp. Med. 152 (1980) 1459-1472.

[16] Cukrowska B., Kozakova H., Rehakova Z., Sinkora J., Tlaskalova-Hogenova H., Specific antibody and immunoglobulin responses after intestinal colonization of germ-free piglets with non-pathogenic Escherichia Coli O86, Immunobiology 204 (2001) 425-433.

[17] Frink S., Grummer B., Pohlenz J.F., LieblerTenorio E.M., Changes in distribution and numbers of CD4+ and CD8+ T- lymphocytes in lymphoid tissues and intestinal mucosa in the early phase of experimentally induced early onset mucosal disease in cattle, J. Vet. Med. B Infect. Dis. Vet. Public Health 49 (2002) 476-483.

[18] Gad M., Regulatory T cells in experimental colitis, Curr. Top. Microbiol. Immunol. 293 (2005) 179-208.

[19] Gerfault V., Louveau I., Mourot J., Le Dividich J., Proliferation and differentiation of stromal-vascular cells in primary culture differ between neonatal pigs consuming maternal or formula milk, J. Nutr. 130 (2000) 1179-1182.

[20] German A.J., Hall E.J., Day M.J., Analysis of leucocyte subsets in the canine intestine, $\mathrm{J}$. Comp. Pathol. 120 (1999) 129-145.

[21] Gorti G.K., Birchall M.A., Haverson K., Macchiarini P., Bailey M., A preclinical model for laryngeal transplantation: anatomy and mucosal immunology of the porcine larynx, Transplantation 68 (1999) 1638-1642.

[22] Green W.B., Eaton K., Krakowka S., Porcine gastric mucosa associated lymphoid tissue (MALT): stimulation by colonization with the gastric bacterial pathogen, Helicobacter pylori, Vet. Immunol. Immunopathol. 56 (1997) 119-131.

[23] Griebel P.J., Kugelberg B., Ferrari G., Two distinct pathways of B-cell development in Peyer's patches, Dev. Immunol. 4 (1996) 263-277.

[24] Haverson K., Riffault S., Antigen presenting cells in mucosal sites of veterinary species, Vet. Res. 37 (2006) 339-358.

[25] Haverson K., Stokes C.R., Bailey M., Immunological structure and antigen-presenting cells in the intestinal lamina propria, Period. Biol. 99 (1997) 335-341.

[26] Haverson K., Singha S., Stokes C.R., Bailey M., Professional and non-professional anti- gen-presenting cells in the porcine small intestine, Immunology 101 (2000) 492-500.

[27] Hayday A., Theodoridis E., Ramsburg E., Shires J., Intraepithelial lymphocytes: exploring the third way in immunology, Nat. Immunol. 2 (2001) 997-1003.

[28] Heppell L.M.J., Sissons J.W., Pedersen H.E., A comparison of the antigenicity of soyabean-based infant formulas, Br. J. Nutr. 58 (1987) 393-403.

[29] Hogenesch H., Felsburg P.J., Immunohistology of Peyer patches in the dog, Vet. Immunol. Immunopathol. 30 (1992) 147-160.

[30] Husby S., Mestecky J., Moldoveanu Z., Holland S., Elson C.O., Oral tolerance in humans T-cell but not B-cell tolerance after antigen feeding, J. Immunol. 152 (1994) 4663-4670.

[31] Imhof B.A., Dunon D., Courtois D., Luhtala M., Vainio O., Intestinal CD8 Alpha Alpha and CD8 Alpha Beta intraepithelial lymphocytes are thymus derived and exhibit subtle differences in TCR Beta repertoires, J. Immunol. 165 (2000) 6716-6722.

[32] Inman C.F., Jones P., Harris C., Haverson K., Miller B., Stokes C., Bailey M., The mucosal immune system of the neonatal piglet, The Pig Journal 55 (2005).

[33] Inman C., Rees L.E., Barker E., Haverson K., Stokes C.R., Bailey M., Validation of computer-assisted, pixel-based analysis of multiple-colour immunofluorescence histology, J. Immunol. Methods 302 (2005) 156-167.

[34] Jump R.L., Levine A.D., Mechanisms of natural tolerance in the intestine - implications for inflammatory bowel disease, Inflamm. Bowel Dis. 10 (2004) 462-478.

[35] Klipper E., Sklan D., Friedman A., Immune responses of chickens to dietary protein antigens - I. Induction of systemic and intestinal immune responses following oral administration of soluble proteins in the absence of adjuvant, Vet. Immunol. Immunopathol. 74 (2000) 209-223.

[36] Mellman I., Steinman R.M., Dendritic cells: specialized and regulated antigen processing machines, Cell 106 (2001) 255-258.

[37] Miller B.G., Whittemore C.T., Stokes C.R., Telemo E., The effect of delayed weaning on the development of oral tolerance to soybean protein in pigs, Br. J. Nutr. 71 (1994) 615625.

[38] Mutwiri G., Watts T., Lew L., Beskorwayne T., Papp Z., Baca-Estrada M.E., Griebel P., Ileal and Jejunal Peyer's patches play distinct roles in mucosal immunity of sheep, Immunology 97 (1999) 455-461. 
[39] Noblet J., Dourmad J.Y., Etienne M., LeDividich J., Energy metabolism in pregnant sows and newborn pigs, J. Anim. Sci. 75 (1997) 27082714.

[40] Paalangara R., McClure S., McCullagh P., Intestinal exposure to a parasite antigen in utero depresses cellular and cytokine responses of the mucosal immune system, Vet. Immunol. Immunopathol. 93 (2003) 91105.

[41] Reynaud C.A., Mackay C.R., Muller R.G., Weill J.C., Somatic generation of diversity in a mammalian primary lymphoid organ - the sheep Ileal Peyers-patches, Cell 64 (1991) 995-1005.

[42] Reynolds J.D., Mitotic rate maturation in the Peyer patches of fetal sheep and in the bursa of Fabricius of the chick-embryo, Eur. J. Immunol. 17 (1987) 503-507.

[43] Reynolds J.D., Kennedy L., Peppard J., Pabst R., Ileal Peyer patch emigrants are predominantly B-Cells and travel to all lymphoid-tissues in sheep, Eur. J. Immunol. 21 (1991) 283-289.

[44] Rothkoetter H.J., Ulbrich H., Pabst R., The postnatal-development of gut lamina propria lymphocytes - Number, proliferation, and Tcell and B-cell subsets in conventional and germ-free pigs, Pediatr. Res. 29 (1991) $237-$ 242.

[45] Solano-Aguilar G.I., Vengroski K.G., Beshah E., Lunney J.K., Isolation and purification of lymphocyte subsets from gut-associated lymphoid tissue in neonatal swine, J. Immunol. Methods 241 (2000) 185-199.

[46] Stokes C.R., Bailey M., Haverson K., Harris C., Jones P., Inman C., Pie S., Oswald I.P., Williams B.A., Akkermans A.D.L., Sowa E., Rothkotter H.J., Miller B.G., Postnatal development of intestinal immune system in piglets: implications for the process of weaning, Anim. Res. 53 (2004) 325-334.

[47] Streatfield S.J., Howard J.A., Plant-based vaccines, Int. J. Parasitol. 33 (2003) 479-493.

[48] Summerfield A., Rziha H.J., Saalmuller A., Functional characterization of porcine CD4(+)CD8(+) extrathymic T lymphocytes, Cell. Immunol. 168 (1996) 291-296.

[49] Telemo E., Bailey M., Miller B.G., Stokes C.R., Bourne F.J., Dietary antigen handling by mother and offspring, Scand. J. Immunol. 34 (1991) 689-696.

[50] Uinuk-ool T., Mayer W.E., Sato A., Dongak R., Cooper M.D., Klein J., Lamprey lymphocyte-like cells express homologs of genes involved in immunologically relevant activities of mammalian lymphocytes, Proc. Natl. Acad. Sci. USA 99 (2002) 14356-14361.
[51] Van den Broeck W., Bouchaut H., Cox E., Goddeeris B.M., F4 receptor-independent priming of the systemic immune system of pigs by low oral doses of F4 fimbriae, Vet. Immunol. Immunopathol. 85 (2002) 171178.

[52] Vega-Lopez M.A., Telemo E., Bailey M., Stevens K., Stokes C.R., Immune cell distribution in the small-intestine of the pig Immunohistological evidence for an organized compartmentalization in the lamina propria, Vet. Immunol. Immunopathol. 37 (1993) 49-60.

[53] Vega-Lopez M.A., Bailey M., Telemo E., Stokes C.R., Effect of early weaning on the development of immune cells in the pig small-intestine, Vet. Immunol. Immunopathol. 44 (1995) 319-327.

[54] Vervelde L., Jeurissen S.H.M., Postnataldevelopment of intraepithelial leukocytes in the chicken digestive-tract - Phenotypical characterization in-situ, Cell Tissue Res. 274 (1993) 295-301.

[55] Waly N.E., Stokes C.R., Gruffydd-Jones T.J., Day M.J., Immune cell populations in the duodenal mucosa of cats with inflammatory bowel disease, J. Vet. Intern. Med. 18 (2004) 816-825.

[56] Wilson A.D., Haverson K., Southgate K., Bland P.W., Stokes C.R., Bailey M., Expression of major histocompatibility complex class-II antigens on normal porcine intestinal endothelium, Immunology 88 (1996) 98-103.

[57] Yasuda M., Tanaka S., Arakawa H., Taura Y., Yokomizo Y., Ekino S., A comparative study of gut-associated lymphoid tissue in calf and chicken, Anat. Rec. 266 (2002) 207217.

[58] Yasuda M., Fujino M., Nasu T., Murakami T., Histological studies on the ontogeny of bovine gut-associated lymphoid tissue: appearance of $\mathrm{T}$ cells and development of $\operatorname{IgG}(+)$ and $\operatorname{IgA}(+)$ cells in lymphoid follicles, Dev. Comp. Immunol. 28 (2004) 357369.

[59] Yu C.L., Dong M.L., Wu X.K., Li S.G., Huang S.F., Su J., Wei J.W., Shen Y., Mou C.Y., Xie X.J., Lin J.G., Yuan S.C., Yu X.S., Yu Y.H., Du J.C., Zhang S.C., Peng X.X., Xiang M.Q., Xu A.L., Genes "waiting” for recruitment by the adaptive immune system: the insights from amphioxus, J. Immunol. 174 (2005) 3493-3500.

[60] Zapata A.G., Cooper E.L., Lymphoid aggregations associated with the gut, lungs and urogenital system, in: Zapata A.G., Cooper E.L. (Eds.), The immune system: Comparative histophysiology, John Wiley and Sons, Chichester, UK, 1990, pp. 232-268. 